\title{
c-fos, UM GENE DE ATIVAÇÃO IMEDIATA COMO MARCADOR NEURAL DE NOCICEPÇÃO
}

\author{
C-FOS, AN IMMEDIATE EARLY GENE AS A NEUROMARKER FOR NOCICEPTION
}

Paulo Tadeu C. Prado \& Elaine A. Del Bel${ }^{2}$

\begin{abstract}
${ }^{1}$ Aluno do 6ªno da Faculdade de Medicina de Ribeirão Preto, bolsista de Iniciação Científica da FAPESP; ${ }^{2}$ Professora, Doutora, MS3 do Departamento de Fisiologia da Faculdade de Odontologia de Ribeirão Preto - Universidade de São Paulo

Correspondência: Elaine A. Del Bel - Av. do Café, s/ noํ, CEP 14040-904, Ribeirão Preto-SP, Brasil. Paulo Tadeu C. Prado - Faculdade de Medicina de Ribeirão Preto - CEP:14049-900 - Campus Universitário - Ribeirão Preto-SP.
\end{abstract}

PRADO PTC \& DEL BEL EA. C-fos, um gene de ativação imediata como marcador neural de nocicepção. Medicina, Ribeirão Preto, 31: 424-433, jul./set. 1998.

RESUMO: A dor é uma experiência complexa, que inclui componentes sensoriais e afetivos, sendo composta por sensações de desprazer, essenciais para o ser humano. A manifestação clínica da dor pode ser interpretada como expressão da capacidade de resposta plástica do sistema nervoso. Existem evidências de que os estímulos nocivos poderiam, também, produzir variações de longa duração nos processos celulares, no SNC, através da modulação da expressão dos genes de ativação imediata como o c-fos e o c-jun. Assim, a distribuição da proteína Fos, em áreas do SNC, após estimulação nociva, térmica, inclui: 1)estruturas envolvidas com respostas emocionais que parecem participar do componente afetivo da dor (núcleos do complexo amigdalóide, hipotálamo e componentes límbicos corticais); 2) estruturas classicamente relacionadas à nocicepção, porém também com atuação sobre o componente afetivo da dor (substância cinzenta, periaquedutal e núcleos da rafe); e 3) áreas com evidências de forte participação na modulação de impulsos nociceptivos (substância cinzenta, periaquedutal e núcleo pré-tectal, anterior). A expressão da proteína Fos, induzida por estímulo nocivo, pode também ter relação com neuroplasticidade à dor patológica e hiperalgesia, bem como com o efeito profilático da "preemptive" analgesia na dor pós-cirúrgica. Enfim, atuando como "terceiros mensageiros" nucleares, o c-fos poderia estimular a síntese de peptídeos opióides, que desempenhariam um papel na modulação da dor. Paralelamente, esse gene pode ser usado como um marcador transináptico de atividade neuronal, após estímulos nocivos, permitindo o estudo de grandes populações de neurônios através da marcação de estruturas centrais, ativadas por estímulo periférico.

UNITERMOS: Genes Fos. Nociceptores. Genes Precoces. Ratos. Dor. Substância Cinzenta Periaquedutal. Imunoistoquímica.

\section{INTRODUÇÃO}

A dor é uma experiência complexa e de múltiplas dimensões, que se origina no sítio da lesão, sendo transmitida pelo sistema nervoso, periférico, processada em diversos níveis no sistema nervoso central e, finalmente, percebida no córtex cerebral. Os impulsos gerados pela lesão tecidual podem ser modifica- dos por sistemas ascendentes, que são ativados por estímulos inócuos ou por estímulos inibitórios descendentes. Estes últimos podem ser ativados por fatores ambientais e psicológicos. Assim, o estudo dos mecanismos nociceptivos demonstrou componentes afetivos e sensoriais, que levam a sensações de desprazer, essenciais para o ser humano. Cada um dos passos da transmissão da dor está sujeito à modulação, po- 
dendo ocorrer redução ou bloqueio da informação nociceptiva, com conseqüente diminuição da dor. A dor alerta o cérebro sobre perigo derivado de estímulo nocivo, fazendo sentido a existência de um subsistema especial, devotado à percepção de circunstâncias potencialmente nocivas. O estímulo doloroso "per si" pode induzir respostas autonômicas ou involuntárias (aumento na frequiência cardíaca, sudorese, variações da pressão sangüínea), alterações do comportamento, resposta de alerta, reflexo muscular e vocalização. Diversos fatores podem modificar as reações dos indivíduos à dor, como o estado emocional, experiências passadas, memória de episódios de dor, magnitude da lesão tecidual ou do estímulo, outras experiências sensoriais concomitantes, assim como a habilidade de compreender as causas da dor (etiologia) e as suas conseqüências. As reações à dor são, via de regra, variáveis, dependendo do grupo étnico e cultural.

A Teoria do Portão de controle da dor, descrita por Melzak \& Wall ${ }^{(1)}$ enfatiza algumas das interações polimodais, envolvidas na dor, embora a base neural da dor não seja completamente entendida. Essa teoria postula "portões", no corno dorsal da medula espinhal, que determinariam quais de toda uma série de influências convergentes, provenientes de receptores sensíveis a estímulos nocivos, táteis e térmicos seriam transmitidas para o SNC, a cada momento em particular. A transmissão do estímulo através do "portão" seria afetada pela intensidade de estímulos nocivos e por fibras mielinizadas de mecanoceptores, assim como por impulsos descendentes de regiões específicas do SNC, como a substância cinzenta periaquedutal, dorsal.

A manifestação clínica da dor pode ser interpretada como expressão da capacidade de modificações na sensibilidade de transdução dos sinais; na excitabilidade das membranas e no fenótipo de neurônios sensoriais, primários; na eficácia sináptica e/ou na circuitaria de neurônios espinhais; ou seja, modificações na capacidade de resposta plástica do sistema nervoso $(\mathrm{SN})^{(2)}$. Tais modificações poderiam ser induzidas pela inflamação e pela lesão de nervos, resultando na redução do limiar e amplificação da resposta algésica.

Este conceito de que a lesão ou o estímulo nocivo possam levar a alterações no $\mathrm{SN}$, e conseqüentemente a uma resposta plástica do Sistema Nervoso Central (SNC), não é nova. Conforme citado por Coderre $^{(2)}$, desde o século passado tem sido proposto que lesões periféricas disparariam mecanismos que produziriam variações na excitabilidade do SNC. Porém, as teorias propostas até agora não fornecem evidências ou detalhes da natureza das modificações moleculares que ocorreriam nas células nervosas após a estimulação nociva, responsáveis pela variação da excitabilidade do SNC. Diversos pesquisadores sugerem a participação de neurotransmissores excitatórios, como o glutamato e o aspartato, nestes processos de sensibilização ${ }^{(3)}$. Teorias recentes propõem a ocorrência de variações celulares e moleculares que influenciariam a excitabilidade das membranas e induziriam a expressão de novos genes, favorecendo a sensibilização das respostas a estimulações subseqüentes ${ }^{(4,5)}$.

Neste sentido, Herdegen \& Zimmermann ${ }^{(6)}$, sugerem que os estímulos nocivos poderiam também produzir variações de longa duração nos processos celulares no SNC, por horas ou dias, através da modulação da expressão dos genes de ativação imediata ou "immediate early genes" (IEGs). Os IEGs foram descritos como uma classe de genes expressados de forma rápida e transitória, passíveis de serem induzidos em células estimuladas por fatores de crescimento, sem a necessidade de utilizar o processo de síntese de novo de proteínas ${ }^{(7)}$. Esses genes aparentemente são expressados de forma diversa, em diferentes áreas do SNC, após estimulação específica ${ }^{(8,9)}$. Os produtos protéicos de IEGs seriam ferramentas importantes, utilizadas para mapeamento da atividade funcional do cérebro, da mesma forma que a captação de 2-Deoxi-Glicose ${ }^{(4)}$.

Em adição, as evidências acumuladas sugerem que as alterações na expressão dos IEGs, no SNC, poderiam promover alterações funcionais, prolongadas, em células neuronais ${ }^{(10)}$, participando, portanto, de mecanismos adaptativos em vias neurais específicas. Assim, os IEGs não devem ser considerados apenas como marcadores de atividade celular in vivo, mas, talvez, como parte da resposta celular à estimulação ambiental significativa, capaz de promover mudanças a longo prazo, em certos aspectos da fisiologia neuronal.

\section{CARACTERÍSTICAS DOS FATORES DE TRANS- CRIÇÃO INDUTÍVEIS}

Inúmeros estudos têm sido realizados para se entender o mecanismo molecular que medeia a expressão dos IEGs. Os IEGs codificam fatores de transcrição que podem ser induzidos (inducible transcription 
factors, ou ITFs). As ITFs constituem um grupo de proteínas nucleares que se ligam a sítios reguladores, promotores e "enhancers" do DNA, controlando a transcrição de inúmeros genes alvos e efetores. Paralelamente, os IEGs codificam também proteínas, enzimas e receptores de membrana (Figura 1). Os ITFs são proteínas expressadas poucos minutos após uma célula eucariótica ter sido submetida a determinados estímulos. A seqüência de eventos, ocorridos entre um estímulo externo a um neurônio e a expressão dos genes, está contida no conceito de "acoplamento estimulação e transcrição"(9), que abrange vários passos. Inicialmente, um estímulo humoral ou sináptico resulta em elevação dos níveis intracelulares de segundos mensageiros, tais como cálcio, AMPc, GMPc. Em seguida, proteínas quinases, citoplasmáticas são ativadas e/ou translocadas para o núcleo. Essas enzimas catalisam a fosforilação de fatores de transcrição constitutivos, que, por sua vez, se ligam a sequiências consensuais de DNA de alta afinidade, na região promotora dos ITFs, e ativam a RNA polimerase II, levando à transcrição de outras proteínas $^{(11 / 17)}$.

O c-fos e o c-jun são protooncogenes da classe dos IEGs e codificam, respectivamente, as proteínas Fos e Jun, que são ITFs ${ }^{(18)}$. Essas proteínas tendem a formar heterodímeros ou homodímeros e, dessa maneira, apresentam afinidade de ligação ao DNA, provocando a ativação de seus genes alvos ${ }^{(19 / 24)}$.
Após a formação do dímero, através de um zíper de leucina ${ }^{(25)}$, o complexo (fator de transcrição funcional ou proteína-ativadora 1 - AP-1), se ligará a uma seqüência gênica específica, o sítio AP-1, reconhecido como essencial para a transcrição basal ou ativada de vários genes ${ }^{(26)}$. Simultaneamente, ao interagir com outros fatores de transcrição, o heterodímero das proteínas Fos e Jun formam uma ligação entre sistemas de segundos mensageiros independentes ${ }^{(27,28)}$. Essas proteínas e outros ITFs atuariam, portanto, como "terceiros mensageiros" nucleares, ligando eventos mediados pelos segundos mensageiros a alterações subseqüentes na expressão gênica ${ }^{(29)}$.

Alguns estudos sugerem que a indução da expressão da proteína Fos depende da elevação dos níveis intracelulares de $\mathrm{Ca}^{++}$, que decorrem de influxo desse íon através de canais de $\mathrm{Ca}^{++}$, sejam eles operados por receptor glutamatérgico, tipo NMDA (N-Methyl-D-Aspartato), ou através de canais de $\mathrm{Ca}^{++}$voltagen dependentes (VSCC), após ativação de receptores por aminoácidos excitatórios, tipo não-NMDA ${ }^{(30)}$. Outras evidências sugerem que a expressão da proteína Fos depende da interação entre o $\mathrm{Ca}^{++}$que adentra o meio intracelular através de canais operados por receptor tipo-NMDA e a estimulação de segundos mensageiros, como diacilglicerol (DAG), que são ligados a receptores metabotrópicos e que são capazes de ativar a proteína quinase $(\mathrm{ERKs})^{(2)}$.

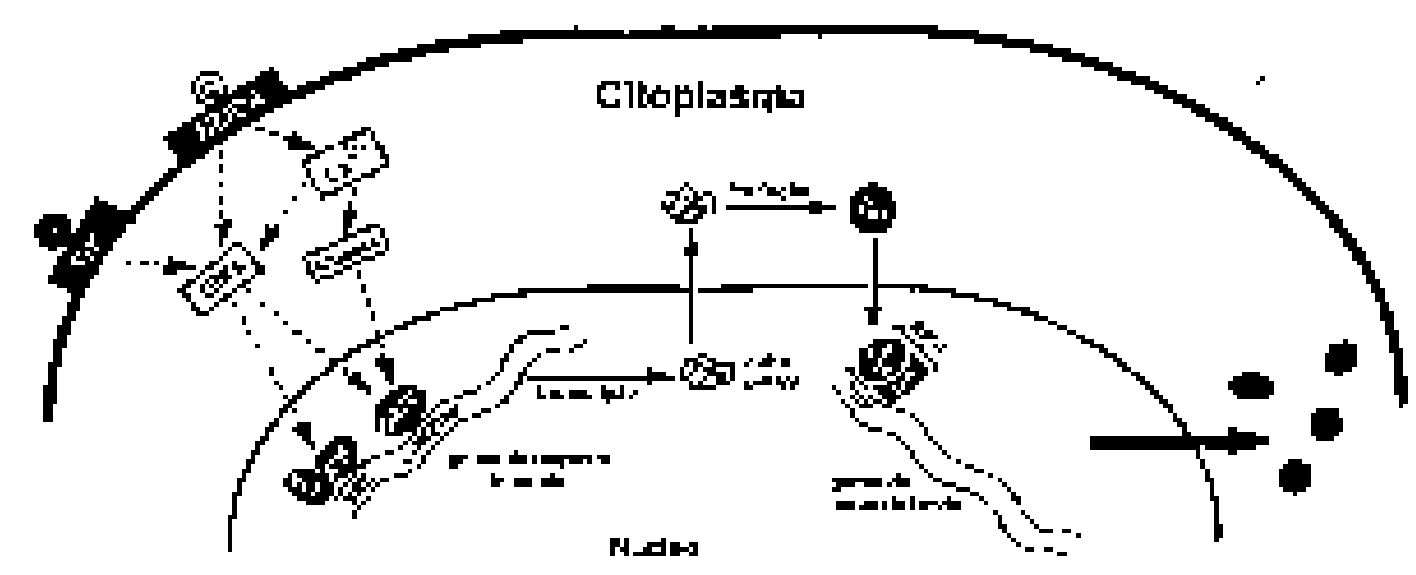

Figura 1 - Representação esquemática das vias moleculares envolvidas na indução do protooncogene c-fos, em neurônios, segundo Chaudhuri (1997), modificado. (G- Glutamato; Nt- neurotrofinas; TrK- receptores de neurotrofinas; CREB, TCF, SRF- fatores de transcrição; SER, CaRE, CRE- seqüências específicas do DNA; TRE- seqüência promotora específica do DNA, ERKs canais ligados a receptores metabotrópicos, estimulação de segundos mensageiros capazes de ativar a proteína quinase). 
A ativação da proteína Fos se dá pelos mais diversos estímulos, como, por exemplo, a despolarização de neurônios ${ }^{(31)}$, estresse ${ }^{(32 / 34)}$, epilepsia ${ }^{(32)}$ e estímulo nociceptivo ${ }^{(35,36)}$, podendo estar envolvida em vários processos fisiológicos.

Evidências experimentais demonstraram que a proteína Fos é expressada pós-sinapticamente em neurônios do corno dorsal da medula espinhal, após estimulação nociva ${ }^{(35)}$. A expressão da proteína Fos no SNC tem início entre uma (1) e duas (2) horas após o estímulo, e atinge um pico após duas (2) horas nas camadas I e II da medula espinhal, ipsilateralmente à estimulação nociva ${ }^{(35)}$. Uma segunda onda de marcação mais tardia, inicialmente ipsilateral e depois bilateral, foi observada nas camadas profundas (V, VI, VII e X) oito (8) horas após o estímulo, com um pico após dezesseis (16) horas ${ }^{37,38}$.

Alguns estudos sugerem que a expressão de Fos em diversas camadas da medula espinhal seja representativa de processos diferentes ${ }^{(39 / 43)}$. Enquanto, em modelos de estimulação nociva, mecânica ou térmica, a expressão de Fos é mais intensa nas camadas I e II da medula espinhal, no modelo da dor produzida pela artrite, induzida por adjuvante de Freund (AIA), a expressão de Fos foi mais intensa nas camadas $\mathrm{V}$ e VI, enquanto as camadas I e II só apresentaram marcação significativa após estimulação mecânica das articulações inflamadas. É interessante notar que o uso de morfina nestes animais suprimiu a expressão de Fos, principalmente nas camadas mais superficiais ${ }^{(41)}$. Em contraste, modelos de dor aguda mostraram maior supressão pela morfina da proteína Fos nas camadas mais profundas ${ }^{(44,45)}$. Além disso, a administração de doses repetidas de naloxone, em ratos submetidos ao modelo AIA, revelou um aumento na expressão de Fos nas camadas profundas, sugerindo a existência de uma atividade tônica de sistemas antinociceptivos, endógenos, em situações de dor crônica ${ }^{(41)}$.

Estudos realizados por Munglani \& Hunt $^{(46)}$, utilizando modelos de dor, após lesão neural, chegaram a resultados que, aliados aos dados expostos acima, permitiram a esses autores concluírem que a associação direta, existente em modelos de dor aguda, entre $c$-fos e intensidade da nocicepção, podem não ser válidos para dor crônica ou para lesão neural crônica. Entretanto, ressaltam que a expressão de Fos, em estados de dor crônica, é duradoura, talvez refletindo alterações moleculares que desencadeiam mudanças fisiológicas, persistentes, como a expressão de genes específicos de fatores indutíveis.

\section{ATIVIDADE NEURAL E ESPECIFICIDADE DE EXPRESSÃO DOS FATORES DE TRANSCRIÇÃO INDUTÍVEIS (ITFs)}

De fato, paralelamente aos achados da marcação de Fos no corno dorsal da medula espinhal, em modelos experimentais de dor artrítica ou de lesão nervosa, uma elevação nos níveis de opióides foi verificada nesses mesmos modelos ${ }^{(47 / 51)}$. Assim, há fortes evidências sugerindo que os genes de pré-prodinorfina e pré-proencefalina (precursores de agonistas opióides kappa e delta, respectivamente) são alvos da proteína Fos. A elevação dos níveis da proteína Fos, cujo pico se dá duas (2) horas após o estímulo periférico, é seguida de uma elevação modesta de RNAm de pré-proencefalina e um grande aumento dos níveis de RNAm de pré-prodinorfina, sendo o pico de ambos após três (3) horas ${ }^{(49)}$. Porém apenas o peptídeo da dinorfina sofre aumento em seus níveis, subseqüentemente ${ }^{(49,52)}$. Além disso, neurônios que apresentam imunorreatividade semelhante à da proteína Fos (FLI ou c-fos-protein-Like Immunorreactivity) têm a mesma localização de neurônios que expressam pré-prodinorfina ou pré-proencefalina ${ }^{(51,53)}$. Tal observação tem sido aceita como uma evidência de que o sinal da proteína Fos está acoplado à transcrição dos genes de dinorfina e encefalina. Aliadas a esses fatos, a presença de um sítio de ligação AP-1, na região promotora do gene da pré-prodinorfina, e a demonstração de que as proteínas Fos e Jun se ligam a esse sítio, nos genes de pré-prodinorfina ${ }^{(54)}$ e pré-proencefalina de ratos $^{(55)}$, corroboram com esta hipótese.

Ainda sustentando essas evidências, animais pré-tratados com oligodeoxinucleotídeo "antisense" de $c$-fos (que bloqueia a expressão desse gene) apresentaram aumento da intensidade da fase tônica, induzida por formalina, e não tiveram qualquer elevação dos níveis de RNAm de pré-prodinorfina, enquanto animais que receberam salina ou oligodeoxinucleotídeo "sense" para $c$-fos apresentaram aumento importante na expressão da proteína Fos e RNAm de pré-prodinorfina. Esses dados foram interpretados como sendo indícios de uma seqüência de eventos que se iniciaria com aumento da transcrição da proteína Fos, desencadeada pela injeção de formalina, seguido da elevação da síntese de RNAm de pré-prodinorfina, que resultaria na produção de peptídeos opióides de dinorfina. Esses peptídeos exerceriam, então, uma ação antinociceptiva modulatória ${ }^{(8)}$, pois sabe-se que a dinorfina, aplicada diretamente à medula espinhal, gera 
hiperalgesia ${ }^{(47,56)}$, assim como tem sido sugerido que a hiperalgesia, observada nesses quadros de dor, é devida à expressão de dinorfina. É possível que um dos papéis dos genes de resposta imediata seja, portanto, estimular a síntese de peptídeos opióides, que desempenhariam um papel na modulação da dor ${ }^{(8)}$.

Gogas et al. ${ }^{(44)}$ concluem que a imunocitoquímica da proteína Fos pode ser utilizada como um meio de monitorar a atividade de grandes populações neuronais, em resposta a estímulos nocivos persistentes; tal conclusão foi discutida e corroborada, recentemente, na revisão apresentada por Harris ${ }^{(5)}$. De fato, há forte correlação entre o comportamento gerado pela dor e o número de células que expressam a proteína Fos $^{(45)}$. É importante destacar o fato de a proteína Fos não ter sido identificada nas células gliais, ependimais ou endoteliais ${ }^{(57)}$. Assim, vários trabalhos têm utilizado a imunorreatividade positiva para a proteína Fos como forma de avaliar a localização de neurônios nocirresponsivos, em especial na medula espinhal ${ }^{(42,58 / 61)}$, mas, também, no cérebro ${ }^{(36,62 / 67)}$. A distribuição da proteína Fos no cérebro, após diversos tipos de estimulação nociva, foi parcialmente homóloga ao que é considerado sistema central da dor.

\section{EXPRESSÃO DA PROTEÍNA FOS APÓS ESTI- MULAÇÃO TÉRMICA NOCIVA}

Temos estudado a distribuição de FLI em áreas do SNC após estimulação nociva, térmica. Dentre as áreas que apresentaram reação positiva para a proteína Fos, pudemos identificar estruturas envolvidas com respostas emocionais que parecem participar do componente afetivo da dor. Podemos citar como exemplos: 1) núcleos do complexo amigdalóide, dentre eles o núcleo medial; 2) o hipotálamo, onde podemos destacar o núcleo paraventricular (Figura 2); 3) componentes límbicos corticais, como o giro do cíngulo. Foram identificadas ainda estruturas classicamente relacionadas à nocicepção, porém, também, com atuação sobre o componente afetivo da dor ${ }^{(68)}$, como a substância cinzenta periaquedutal e núcleos da rafe. Finalmente, foi obtida marcação para a proteína Fos em áreas com evidências de forte participação na modulação de impulsos nociceptivos, como a substância cinzenta periaquedutal, particularmente na região ventral, e o núcleo pré-tectal anterior (Figura 2). É interessante notar, no entanto, que, ao contrário da marcação encontrada na maioria dos outros núcleos, a marcação no núcleo pré-tectal, anterior foi unilateral. Algumas regiões como a substância cinzenta peria- quedutal e núcleos talâmicos e hipotalâmicos mediais também apresentaram reação positiva para a proteína Fos após estímulo nocivo, podendo ser relacionadas ao estresse e componentes aversivos da situação nociva. Duas outras áreas marcadas merecem considerações: a camada cinzenta intermediária do colículo superior e o núcleo pré-tectal olivar. É interessante que, embora estejam relacionadas à condução de impulsos gerados por estímulos visuais, ambas foram marcadas após estimulação nociva.

O entendimento da manifestação clínica da dor e o desenvolvimento de novas terapias têm sido apoiados fortemente no conhecimento do componente afetivo da dor, o que demonstra a importância do estudo dos componentes afetivo e sensorial da dor. A dor é uma experiência muito individual; tal fato é demonstrado pela grande variabilidade na intensidade de dor descrita por pacientes com lesões semelhantes, mostrando que deve haver diferença entre a realidade objetiva da dor e a resposta subjetiva, embora a intensidade ou severidade da dor seja freqüentemente relacionada ao grau de lesão do tecido. Outro fator que demonstra o componente afetivo da dor seria o efeito analgésico obtido com a aplicação de placebo, remédios farmacologicamente inertes. O efeito não é mágico ou sinal de intelecto sugestivo.

\section{CONSIDERAÇÕES FINAIS}

Há aproximadamente uma década, Hunt et al. ${ }^{(35)}$ descreveram a expressão do gene $c$-fos e seu produto protéico, a proteína Fos, em neurônios do corno dorsal da medula espinhal, lombar, de ratos, submetidos à estimulação nociva. Desde então, a análise da expressão da proteína Fos tem sido utilizada em estudos das bases neurais da nocicepção. Existem algumas vantagens na utilização da proteína Fos como uma ferramenta para estudar a nocicepção. Em primeiro lugar, em comparação com outras técnicas, é relativamente fácil identificar a localização precisa de grupos neuronais que respondem à estimulação nociva. Segundo, a expressão de $c$-fos pode ser analisada quantitativamente, simplesmente através da contagem dos neurônios marcados, seja através da imunocitoquímica para a proteína Fos, seja através da hibridização in situ para o RNAm de $c$-fos. Em adição, a marcação imunocitoquímica da proteína Fos pode ser realizada em combinação com a marcação de outros antígenos ou com traçadores neurais, tornando possível a identificação das características dos neurônios que expressam $c$-fos, em resposta a estimulação nociva. 


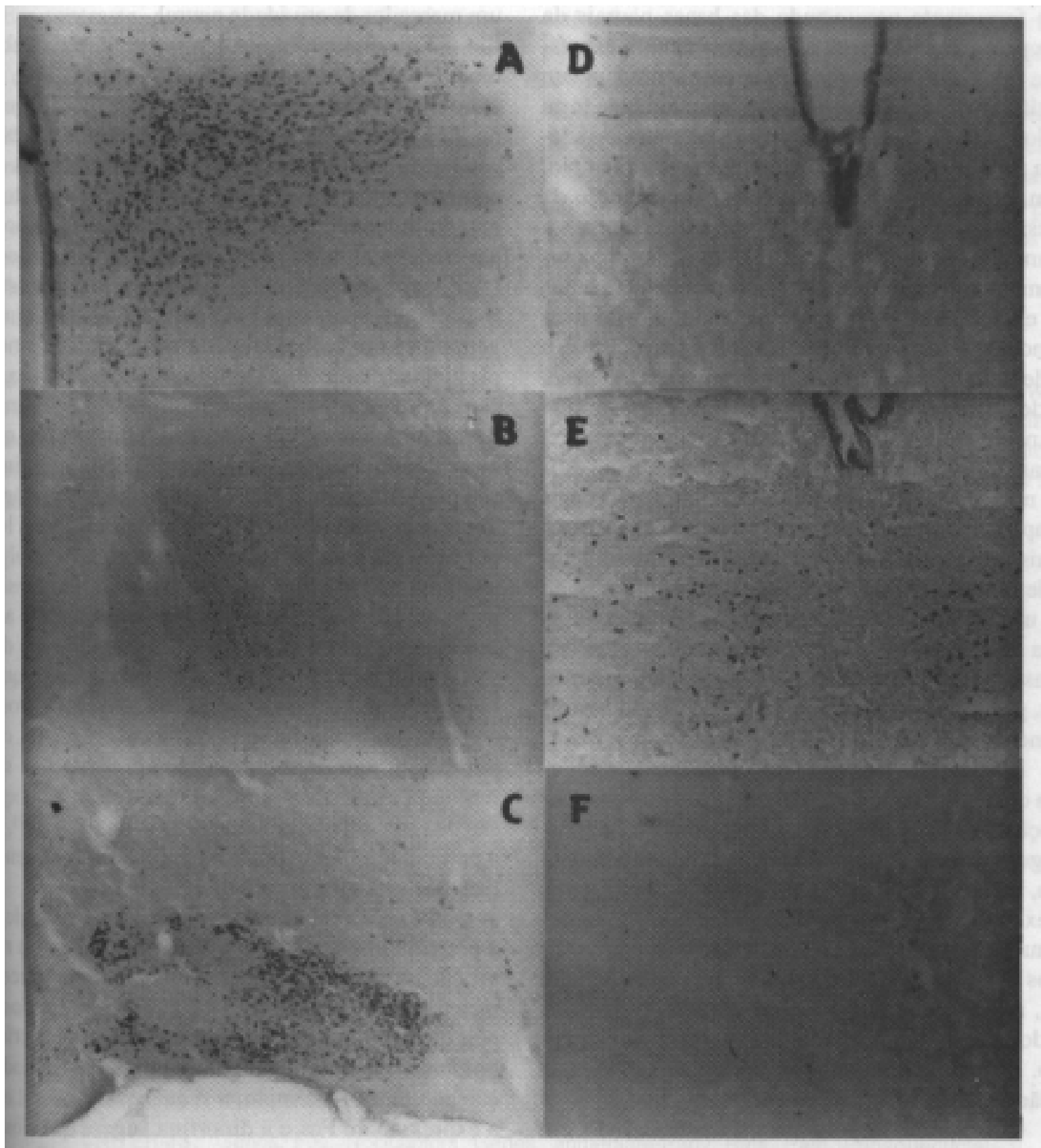

Figura 2 - Expressão da proteína Fos detectada por imunocitoquímica, em cérebros de ratos submetidos à estimulação térmica nociva aguda na pata posterior esquerda. Note a marcação de estruturas envolvidas com respostas emocionais que parecem participar do componente afetivo da dor como: (A) o núcleo paraventricular do hipotálamo, (B) núcleos do complexo amigdalóide e (C) córtex piriforme, uma estrutura límbica cortical; estruturas classicamente relacionadas à nocicepção, porém, também, com atuação sobre o componente afetivo da dor como (D) substância cinzenta periaquedutal e (E) núcleos da rafe; áreas com evidências de forte participação na modulação de impulsos nociceptivos, como (F) $o$ núcleo pré-tectal anterior. 
No entanto, o conhecimento dos numerosos problemas associados com o uso da expressão de $c$-fos como ferramenta para estudo das bases neurais da nocicepção também é crítico. Primeiramente, a expressão de c-fos, em níveis que possam ser acuradamente quantificados, requer estimulação relativamente forte e prolongada, em comparação com a estimulação adequada para medidas eletrofisiológicas, por exemplo. Assim, talvez os parâmetros ideais para detecção da expressão da proteína Fos por estímulo nociceptivo possam não ser aqueles ideais para medidas do comportamento dos animais. Outro problema, ao examinar a expressão de $c$-fos como marcador de vias neurais, nociceptivas, é o resultado falso, negativo, isto é, o fato de nem todos os neurônios expressarem o gene, quando ativados. Isto significa que podem existir discrepâncias entre os neurônios que efetivamente expressam o gene, quando o animal é submetido ao estímulo nociceptivo e os neurônios ou núcleos neuronais que, aparentemente, estariam envolvidos nos processos neurais nociceptivos, evidenciados por outros métodos de medida. Assim, a ausência da expressão de $c$-fos não pode ser entendida como identificação de ausência de atividade neural. Os pesquisadores precisam ser bastante cuidadosos, quando interpretam os resultados, particularmente porque os neurônios podem diferir no limiar para indução da expressão de $c$-fos.

Finalmente, além do risco da interpretação errônea de falsos negativos, há também o risco da identificação de falsos positivos. O problema surge porque, geralmente, é muito difícil determinar o evento exato, responsável direto pela estimulação do gene. Por exemplo, a expressão de $c$-fos, observada após estímulo nociceptivo pode estar relacionada aos processos nociceptivos, mas, igualmente, pode estar, em parte, relacionada à resposta de estresse, provocada pela dor ou à atividade motora, produzida pela estimulação. Este problema pode ser controlado através da seleção cuidadosa de grupos controle.

Outro ponto importante a ser considerado, em estudos de nocicepção, seria a questão de qual seria exatamente o papel de Fos nos processos nociceptivos. Como já destacado anteriormente, a expressão de ITFs, incluíndo a proteína Fos, tem sido utilizada como um marcador de atividade neuronal e indica a ativação de diversos processos, a nível nuclear, em determinadas populações de neurônios. Dessa forma, a identificação imunocitoquímica de Fos e/ou de outros ITFs torna-se um valioso instrumento de estudo das alterações das funções neuronais que envolvem ativação de processos de transcrição com subseqüente síntese, de novo, de proteínas ${ }^{(6)}$. Contudo, o entendimento da função de Fos deve ir além de seu uso como um marcador da atividade neural.

Existem evidências crescentes da existência de uma relação entre a expressão da proteína Fos, induzida por estímulo nocivo e a modulação, por longo tempo, dos processos nociceptivos espinhais. Esses processos resultariam em alterações nos circuitos nociceptivos espinhais (neuroplasticidade à dor patológica), promovendo o aumento da sensibilidade ao estímulo nocivo (hiperalgesia) ou a estímulos não nocivos (alodinia $^{(2)}$. Assim, tem sido observado que o estímulo nocivo, responsável pela indução de Fos, também gera hiperalgesia, a qual pode ser associada à neuroplasticidade central. Além disso, o tempo de expressão da proteína Fos coincide com o desenvolvimento de hiperalgesia. Tem sido descrito, ainda, que a hiperalgesia é evidente em casos onde uma estimulação periférica inicia, mas não mantém a hiperalgesia. Tendo isso em vista, é interessante notar que a lesão, por calor, da pata posterior de ratos gera hiperalgesia imediata na pata lesada, seguida de hiperalgesia na pata contralateral (não lesada), após quatro (4) a vinte e quatro (24) horas, decorridas do momento da lesão. Este tempo é o mesmo decorrido para que se observe uma "segunda onda" de atividade Fos em ambos os cornos posteriores da medula espinhal, como já descrito anteriormente. Essas observações sugerem uma associação entre a hiperalgesia e a expressão de Fos com plasticidade neural, após lesão( ${ }^{(2)}$, com a participação dessa proteína no processo de sensibilização da medula espinhal.

No entanto, existem evidências diretas de que a proteína Fos estaria envolvida na inibição da nocicepção na medula espinhal. Atuando como "terceiros mensageiros" nucleares, é possível que um dos papéis desses genes seja estimular a síntese de peptídeos opióides, que desempenhariam um papel na modulação da dor. Por exemplo, a sequência temporal entre a expressão de Fos e a dinorfina sugere que Fos poderia regular a expressão do gene da pré-prodinorfina. Assim, através da indução da síntese de peptídeos opióides na medula espinhal, a proteína Fos poderia participar da antinocicepção prolongada.

O conceito de "pre-emptive" analgesia, ou seja, do efeito profilático da pré-medicação com opióides e/ou bloqueio no nervo com anestésico local, sobre a dor pós-cirúrgica, desenvolveu-se diretamente de pesquisa básica em animais. Os estudos sugeriram que hiperexcitabilidade espinhal, induzida pela lesão, e comportamentos associados com a dor podem ser 
bloqueados, se os animais receberem opióides ou anestésicos locais antes da estimulação nociva ou da lesão. Em contraste, o mesmo tratamento é muito menos efetivo, quando administrado somente alguns minutos depois, uma vez que a excitabilidade central persistente e o comportamento já teriam sido elicitados. Woolf \& Wall ${ }^{(69)}$ descreveram que a dose de morfina, administrada sistemicamente, necessária para bloquear a hiperexcitabilidade da medula espinhal, já estabelecida, era dez vezes maior que aquela necessária para prevenir a excitabilidade, pelo pré-tratamento. Assim, as evidências indicam que a dor pós-cirúrgica pode ser reduzida pelo bloqueio do "portão aferente" para o SNC e do aumento da resposta central que possa vir a ocorrer como consequiência ${ }^{(2)}$. Novamente, a relação temporal entre a aplicação do bloqueio, a expressão de Fos e a efetividade da analgesia por opióides poderia sugerir o envolvimento da proteína Fos neste tipo de indução de analgesia.
Dessa forma, o $c$-fos pode ser usado como um marcador transináptico, de atividade neuronal, após estímulos nocivos, permitindo o estudo de grandes populações de neurônios através da marcação de estruturas centrais, que podem ser ativadas por estímulo periférico ${ }^{(4,5)}$. Paralelamente, ao fazer a ligação de eventos mediados pelos segundos mensageiros a alterações subseqüentes, na expressão gênica, eles também constituem instrumentos importantes para o estudo de alterações funcionais dos neurônios após estímulos periféricos.

\section{AGRADECIMENTOS}

Agradecemos a colaboração dos Profs. Drs. Wiliam Alves do Prado e Francisco Silveira Guimarães; o auxílio técnico de José Carlos Aguiar, Célia A da Silva, Eleni L Tamburus Gomes, Paulo Castania, Sara Saltareli, Renata Caldo e Frankie Pitta. Apoio financeiro: FAPESP, FAEPA, CNPq.

PRADO PTC \& DEL BEL EA. C-fos, an immediate early gene as a neuromarker for nociception. Medicina, Ribeirão Preto, 31: 424-433, july/sept. 1998.

ABSTRAT: Pain is a complex experience that involves sensorial and affective components, and is composed by displeasure sensation, which are important for human being. Clinical manifestation of pain may be understood as the expression of nervous system ability for plastic response. There is evidence showing that nocive stimulation could also induce long-term variation in CNS cellular processes by modulating the expression of immediate early genes such as $c$-fos and $c$-jun. Fos protein distribution in CNS areas following heat nocive stimulation includes: 1) structures involved in emotional responses that seem to play a role in the affective component of pain (amygdaloid complex, hypothalamus, and cortical limbic structures); 2) structures usually responsible for descending pain control systems, that also play a role in the affective component of pain (periaqueductal gray and raphe nuclei); and 3) regions with evidence of taking part on the modulation of nociceptive impulse (periaqueductal gray and anterior pretectal nucleus). Expression of Fos protein in CNS following nocive stimuli may also be related to neuroplasticity in pathological pain and hiperalgesia, as well as to the prolific effect of the "pre-emptive" analgesia in pain following surgeries. In addition, as a nuclear "third messenger", c-fos could stimulate synthesis of opioid peptide, which would play a role in pain modulation. Finally, this gene could be used as a transinaptic marker for neuronal activity, which allow the study of large neuronal population of structures that are activated by periferic stimulation.

UNITERMS: Genes, Fos. Nociceptors. Genes, Immediate-Early. Rats. Pain. Periaqueductal Gray. Immunohistochemistry.

\section{REFERÊNCIAS BIBLIOGRÁFICAS}

1 - MELZAK R \& WALL PD. Pain mechanisms: A new theory. Science 150: 971-979, 1965.

2 - CODERRE TJ et al. Contribution of central neuroplasticity to pathological pain: review of clinical and experimental evidence. Pain 52: 259-285, 1993.
3 - WILCOX GL. Excitatory neurotransmitters and pain. In: CHARLTON JE \& WOOLF CJ, eds. Pain research and management, Proc. $\mathrm{V}^{\text {th }}$ World Congress on Pain, Elsevier, Amsterdan, v. 4, p. 97-117, 1991.

4 - CHAUDHURI A. Neural activity mapping with inducible transcription factors. Neuroreport 8: 8:13, 1997.

5 - HARRIS J A. Using c-fos as a neural marker of pain. Brain Res Bull 45: 1-8, 1998. 
6 - HERDEGEN T \& ZIMMERMANN M. Immediate early genes encoding for inducible transcription factors and neuropeptides in the nervous system: functional network for longterm plasticity and pain. Prog Brain Res 104: p. 299-321, 1995.

7 - COCHRAN BH, REFFELAC \& STILES CD. Molecular cloning of genes sequences regulated by platelet-derived growth factor. Cell 33: 939-947, 1983.

8 - HUNTER JC et al. c-fos antisense oligodeoxynucleotide increase formalin-induced nociception and regulates preprodynorphin expression. Neuroscience 65: 485-492, 1995.

9 - MORGAN JI \& CURRAN T. Stimulus-transcription coupling in the nervous system: involvement of the inducible protooncogenes fos and jun. Annu Rev Neurosci 14: 421-451, 1991.

10 - GOELET $P$ et al. The long and the short of long-term memory - a molecular framework. Nature 322: 418-422, 1986.

11 - BADING H, GINTY DD \& GREENBERG ME. Regulation of gene expression in hippocampal neurons by distinct calcium signaling pathways. Science 260: 181-186, 1993.

12 - GINTY DD, BADING H \& GRENNBERG ME. Transinaptic regulation of gene expression. Neurobiology 2: 312-316, 1992.

13 - GINTY DD et al. Regulation of CREB phosphorylation in suprachiasmatic nucleus by light and circadian clock. Science 260: 238-341, 1993.

14 - GONZALES GA et al. A cluster of phosphorilation sites on the cyclic AMP-regulated nuclear factor Creb predicted by its sequence. Nature 337: 749-752, 1989.

15 - SHENG M. Membrane depolarization and calcium induce cfos transcription via phosphorilation of transcription factor CREB. NEURON 4: 571-582, 1990.

16 - TREISMAN R. The SER: A growth factor responsive transcriptional regulator. Cancer Biol 1: 47-58, 1990.

17 - van DAM H et al. Heterodimer formation of $c$-jun and ATF-2 is responsible for induction of $\mathrm{C}$-jun by the 143 amino acid adenovirus E1A protein. EMBO J 12: 479-487, 1993.

18 - CURRAN T \& MORGAN Jl. Memories of Fos. BioEssays 7: 255-258, 1987

19 - ANGEL P et al. Oncogene jun encodes a sequence-specific trans-activator similar to AP-1. Nature 332: 166-171, 1988.

20 - GENTZ R et al. Paralell association of Fos and Jun leucine zipers juxtaposes DNA binding domains. Science 243: 1695-1699, 1989.

21 - HALOZONETIS TD et al. c-jun dimerizes with itself and with c-fos forming complexes of different DNA binding affinties. Cell 55: 917-924, 1988.

22 - NAKABEPPU Y, RYDER K \& NATHANS D. DNA binding activities of three different jun proteins: stimulation by Fos. Cell 55: 907-915, 1988.

23 - RAUSCHER FJ et al. Fos and jun bind cooperatively to the AP-1 site: reconstitution in vitro. Genes Dev 2: 1687-1699, 1988.
24 - RYZECK P \& BRAVO R. c c-jun, Jun B and JunD differ in their binding affinities to AP-1 and CRE consesus sequences: effects of Fos proteins. Oncogene 6: 533-542, 1991.

25 - LANDSHULTZ WH, JOHNSON PF \& MCKNIGHT SL. The leucine zipper: a hypothetical structure common to a new class of of DNA binding proteins. Science 240: 1759-1764, 1988.

26 - CURRAN T \& FRANZA Jr BR. Fos and Jun: the AP-1 connection. Cell 55: 395-397, 1988.

27 - HAGMEYER BM et al. Adenovirus E1A negatively and positively modulates transcription of AP-1 dependent genes by dimer-specific regulation of the DNA binding and transactivation activities of Jun. EMBO J 12: 3559-3572, 1993.

28 - HAI T \& CURRAN T. Croos-family dimerization of transcription factors Fos/JUN AND atf/creb alters DNA binding specificity. Proc Natl Acad Sci USA 88: 3720-3724, 1991.

29 - MORGAN JI \& CURRAN T. Calcium as a modulator of the immediate-early gene cascade in neurons. Cell Calcium 9: 303-311, 1988.

30 - LEREA LS, BULTER LS \& MCNAMARA JO. NMDA and nomNMDA receptor mediated increase of $c$-fos $M R N A$ in dentate gyrus neurons involves calcium influx via different routes. $\mathbf{J}$ Neurosci 12: 2973-2981, 1992.

31 - MORGAN JI \& CURRAN T. Role of ion flux in the control of cfos expression. Nature 322: 552-555, 1986.

32 - DEL BEL EA et al. Induction of the c-fos proto-oncogene in the rat pineal gland during stress. Braz J Med Biol Res 26: 975-981, 1993.

33 - TIETZE DE ALMEIDA R et al. Stress-induced expression of c-fos proto-oncogene in the hippocampal formation. Braz $\mathbf{J}$ Med Biol Res 27: 1087-1088, 1994.

34 - TIETZE DE ALMEIDA R et al. Midazolam and the N-Methyl-Daspartate (NMDA) receptor antagonist 2-amino7phosphoheptanoic acid (AP-7) attenuate stress-induced expression of c-fos mRNA in the dentate gyrus. Cell Mol Neurobiol 14: 373-380, 1994

35 - HUNT SP; PINI A \& EVAN G. Induction of c-fos-like protein in spinal cord neurons following sensory stimulation. Nature 328: 632-634, 1987.

36 - HARRIS J A. Descending antinociceptive mechanisms in the brainstem: Their role in the animals defensive system. J Physiol (Paris) 90: 15-25, 1996.

37 - WILLIAMS $S$ et al. Molecular events in the spinal cord following sensory stimulation. In: CERVERO F; BENNETT GJ \& HEADLEY PM, eds. Sensory processing in the superficial dorsal horn of the spinal cord, Plenum Press, New York, p. 273-284, 1989.

38 - WILLIAMS S; EVANS GI \& HUNT SP. Changing patterns of Fos induction in spinal neurons following thermal cutaneous stimulation in the rat. Neuroscience 36: 73-81, 1990.

39 - ABBADIE C \& BESSON J-M. c-fos expression in rat lumbar spinal cord during the development of adjuvant-induced arthritis. Neuroscience 48: 985-993, 1992.

40 - ABBADIE C \& BESSON J-M. c-fos expression in rat lumbar spinal cord following peripheral stimulation in adjuvant-induced arthritic and normal rats. Brain Res 607: 195-204, 1993. 
41 - ABBADIE C \& BESSON J-M. Effects of morphine and naloxone on basal and evoked Fos-like immunorreactivity in lumbar spinal cord neurons of arthritic rats. Pain 52: 29-39, 1993.

42 - ABBADIE C; BESSON J-M \& CALVINO B. c-fos expression in the spinal cord and pain related symptoms induced by chronic arthritis in the rat are prevented by pretreatment with Freunds adjuvant. J Neurosci 14: 5865-5871, 1994.

43 - ABBADIE $C$ et al. Effects of opioids and non-opioids on cfos-like immunoreactivity induced in rat lumbar spinal cord neurons by noxious heat stimulation. Eur $\mathbf{J}$ Pharmacol 258: 215-227, 1994.

44 - GOGAS KR et al. The antinociceptive action of supraspinal opioids results from an increase in descending inhibitory control: correlation of nociceptive behaviour and $c$-fos expression. Neuroscience 42: 617-628, 1991.

45 - PRESLEY RW et al. Systemic morphine suppresses noxious stimulus-evoked Fos protein-like immunorreactivity in the rat spinal cord. J Neurosci 10: 322-335, 1990.

46 - MUNGLANI R; \& HUNT SP. Molecular biology of pain. Br J Anaesth 75: 186-192, 1995.

47 - DUBNER R \& RUDA MA. Activity dependent neuronal plasticity following tissue injury and inflamation. Trends Neurosci 15: 96-103, 1992.

48 - HUNT S et al. Changes in immediate early genes, neuropeptides immunorreactivity and other neuronal markers in the spinal cord and dorsal root ganglion in a rat model of neuropathic pain. In: HÖKFELT T; SCHAIBLE H-G \& SCHIMIDT RF, eds. Neuropeptides, nociception and pain, Chapman Hall, London, p. 329-349, 1993.

49 - IADAROLA MJ et al. Differential activation of spinal cord dynorphin and enkephalin neurons during hyperalgesia: evidence using cDNA hybridization. Brain Res 455: 205-212, 1988.

50 - MILLAN MJ et al. A model for chronic pain in the rat: response of multiple opioid systems to adjuvant-induced arthritis. J Neurosci 6: 899-906, 1986.

51 - NOGUCHI K et al. Dynorphin expression and Fos-like immunorreactivity following inflammation induced hyperalgesia are co-localized in spinal cord neurons. Molec Brain Res 10: 227-233, 1991.

52 - WEIHE E et al. Induction of gene encoding Pro-dynorphin by experimentally induced arthritis enhances staining for dynorphin in the spinal cord of rats. Neuroscience 31: 77-95 1989.

53 - NOGUCHIK; DUBNERR \& RUDA MA. Preproenkephalin mRNA in spinal dorsal horn neurons is induced by peripheral inflammation and is co-localized with Fos and Fos-related proteins. Neuroscience 46: 561-570, 1992.

54 - NARANJO JR et al. Molecular pathways of pain: Fos/Junmediated activation of a noncanonical AP-1 site in the prodynorphin gene. Neuron 6: 607-617, 1991.

55 - SONNEMBERG JL et al. Regulation of proenkephalin by Fos and Jun. Science 246: 1622-1625, 1989.

56 - KNOX R \& DICKENSON A. Effects of selective and non-selective kappa-opioid receptor agonists on cutaneous C-fibre evoked responses of the rat dorsal horn neurones. Brain Res 415: 21-29, 1987.

57 - MUGNAINI E et al. c-fos-like immunoreactivity induced by seizure is specifically associated with euchromatin in neurons. Eur J Neurosci 1: 46-52, 1989.

58 - BULLITT E. et al. The effect of stimulus duration on noxiousstimulus induced c-fos expression in the rodent spinal cord. Brain Res 580: 172-179, 1992.

59 - CINTRA A; MOLANDER C \& FUXE K. Colocalization of Fos and glucocorticoid receptor-immunoreactivities is present only in a very restricted population of dorsal horn neurons of the rat spinal cord after nociceptive stimulation. Brain Res 632: 334-338, 1993.

60 - HERDEGEN T et al. Increase in nitric oxide synthase and colocalization with Jun, Fos and Krox proteins in spinal neurons following noxious peripheral stimulation. Mol Brain Res 22: 245-258, 1994.

61 - MORGAN MM; GOGAS KR \& BASBAUM AI. Diffuse noxious inhibitory controls reduce the expression of noxious stimulus-evoked Fos-like immunoreactivity in the superficial and deep laminae of the rat spinal cord. Pain 56: 347-352, 1994.

62 - BULLITT E. Induction of c-fos-like protein within the lumber spinal cord and thalamus of the rat following peripheral stimulation. Brain Res 493: 391-397, 1989.

63 - BULLITT E. Expression of c-fos-like protein as a marker for neuronal activity following noxious stimulation in the rat. $\mathbf{J}$ Comp Neurol 269: 517-530,1990.

64 - HONKANIEMI $\mathrm{J}$ et al. Fos and Jun in central amygdaloid nucleus after stress. Neuroreport 3: 849-952, 1992.

65 - LANTERI-MINET M et al. Spinal and hindbrain structures involved in visceroception and visceronociception as revealed by expression of Fos, Jun and Krox-24 proteins. Neuroscience 55: 737-753, 1993.

66 - LANTERI-MINET M et al. Hindbrain structures involved in pain processing, as revealed by the expression of $c$-fos and other immediate early genes proteins. Neuroscience 58: 287-298, 1994.

67 - PERTOVAARA A; HERDEGEN T \& BRAVO R. Induction and suppression of immediate-early genes by selective alpha-2adrenoceptor agonist and antagonist in the rat brain following noxious peripheral stimulation. Neuroscience 54: 117-126, 1993.

68 - BONICA JJ. Biochemistry and modulation of nociception and pain. In: BONICA JJ, ed. The management of pain. Lea \& Febiger. Pensylvannia, v. 1, p. 95-121, 1990.

69 - WOOLF CJ \& WALL PD. Morphine-sensitive and morphine insensitive actions of c-fibre input on the rat spinal cord Neurosci Lett 64: 221-225, 1986.

Recebido para publicação em 08/06/98.

Aprovado para publicação em 01/09/98. 